\title{
8-12 Eylül 2009 Tarihlerinde Marmara Bölgesi’nde Meydana Gelen Sel Olayının Yağıș Analizi
}

\author{
Rainfall analysis of the flood event that occurred in Marmara Region on 8-12 \\ September 2009
}

\author{
Ali Ümran Kömüşcü ${ }^{*}$, Seyfullah Çelik, Abdullah Ceylan \\ Devlet Meteoroloji İşleri Genel Müdürlüğü, Kalaba, Ankara
}

Öz: Trakya'da ve özellikle Istanbul ve civarında 8-12 Eylül 2009 tarihleri arasinda yaşanan sel afeti, 1957 Ankara ve 1995 İzmir sel afetlerinden sonra ülkemizde en fazla can kaybının yaşandı̆̆ sel afetleri arasında yer almıştır. Tarihin en büyük sel afetlerinden birini yaşayan Trakya bölgesi selden ciddi ölçüde etkilenmiş ve afet 32 can kaybu ile 3 bin 816 konut ve bin 490 işyerinin zarar görmesine neden olmuştur. Dere yataklarının yakınındaki fabrika, otoyol, köprü gibi yapılar dışında dere yatağının yakınına kurulan yerleşim yerlerinde yaşayan insanlar selden en çok zararl gören grup olmuştur. Bu çalışmada, 8-12 Eylül 2009 tarihlerinde Trakya'da ve özellikle İstanbul ve civarında sel afetine zemin hazırlayan şiddetli yağışların klimatolojik analizi yapılarak sel afeti ile iliş̧kilendirilmiştir. Bölgede yağışlar 7 Eylül 2009 tarihinde Trakya'nın batısında başlamış ve 8 Eylül 2009 tarihinde ise bölgenin büyük bölümünü içine alacak şekilde artarak devam etmiştir. Bölgede kaydedilen 24-saat yağış miktarları Bandırma'da 253 mm, Çatalca'da 205 mm, Erdek'te 170 mm ve Silivri'de 128 mm olarak kaydedilmiştir. Tüm Marmara Bölgesi için 7-10 Eylül 2009 tarihlerinde gerçekleşen 4-günlük ortalama yağış miktarı ise $74.1 \mathrm{~mm}$ olarak gerçekleşmiştir. Bu rakam eylül ayı uzun yıllar ortalaması olarak belirlenen 36,3 mm'nin iki katıdır. Yağış değerleri dışında, hesaplanan atmosfer kararsızlık indisleride taşkın öncesi dönemde şiddetli hava koşullarının uyarıcısı niteliğindedir. Uydu ve radar verileri de özellikle 7-9 Eylül tarihlerinde bölgede etkili olan şiddetli yă̆ışların varlığını ortaya koymaktadır.

\begin{abstract}
Anahtar kelimeler: İstanbul, sel afeti, meteorolojik koşullar, şiddetli yă̆lş, kararsızlık indis değerleri.
Abstract: A series of flash floods occurred between 8-12 September, 2009 in Thrace part of the Marmara region, and especially in Istanbul and its vicinity. The region was heavily affected from floods that occurred as a result of thunderstorms with torrential rains that swept the region which received its heaviest rainfall in the last 80 years The events were noted as the third deadliest floods after the 1957 Ankara and 1995 Izmir floods.. The floods led to the death of at least 32 people and caused extensive damage to both public and private properties in the region. This study examines climatology of rainfall conditions that led to the flash floods in theThrace part of the Marmara region, and especially Istanbul and its vicinity. The spatial and temporal distribution of the rainfall indicated that the severe storms first affected the western parts of the Marmara region and then covered the entire Istanbul, Silivri and Çatalca where the impact was felt most severely. The 24-hr rainfall amounts mostly varied between 100-253 $\mathrm{mm}$ in the region during those 4 days between 7-10 September 2009. The highest 24-hr rainfall amounts were recorded at Bandirma, Çatalca, Erdek, and Silivri stations with $253 \mathrm{~mm}, 205 \mathrm{~mm}$, $170 \mathrm{~mm}$, and $128 \mathrm{~mm}$ respectively. Average rainfall for the Marmara region was $74.1 \mathrm{~mm}$ considering the 4-day cumulative rainfall recorded between 7-10 September 2010. This amount is considerably over the long term normals for month of September, which is $36,3 \mathrm{~mm}$. It is noted that almost all the instability indices values signalled severe weather situation and storm development prior to the flooding. Areal distribution of the severe rainfalls are portrayed better with the radar and satellite images analyzed for the flooding days in Istanbul and vicinity.
\end{abstract}

Key Words: Istanbul, flash flood, severe rainfall, instability indices, radar and satellite images.

\footnotetext{
* İletişim yazarı: A.Ü. Kömüşcü, e-posta: aukomuscu@dmi.gov.tr
} 


\section{Giriş}

İnsanlar için fiziksel, ekonomik ve sosyal kayıplara neden olan, normal yaşamı kesintiye uğratarak toplumları etkileyen ve yerel imkânlar ile baş edilemeyen her türlü doğal, teknolojik veya insan kaynaklı olaylara" afet denilmektedir (Kadıŏlu, 2006; 2008). Doğal afetler genelde atmosfer kökenli olup, sel ve taşkınlar ise en yaygın görülen meteorolojik karakterli doğal afetlerin başında gelmektedir (Kömüşçü ve Ceylan, 2007). Sel,suyun doğal ya da yapay yatağından taşarak çevre, yerleşim yerleri ve tarım alanlarında tehlikeye neden olması olarak tanımlanabilir. Sel birkaç gün veya daha uzun süre içinde oluşabileceği gibi, saat dilimleri ile ifade edilebilecek kadar kısa sürede meydana gelen ani seller (flash floods) şeklinde de ortaya çıkabilir. Ani seller küçük dere ve nehirlerin ani ve kuvvetli bir yağışa maruz kalmalarıyla oluşur ve akım değerlerini çok hızlı bir şekilde en üst düzeye ulaştırır. Sele sebep olan en önemli meteorolojik parametre yağışın şiddeti, süresi ve karakteristiğidir. Yağış öncesi zeminin nemlilik durumu, yüzey geçirgenliği ve sele maruz kalan bölgenin fiziki coğrafya koşulları da sellerin oluşmasındaki diğer önemli faktörlerdir. Seller, kar erimesi sonucu oluşan kuvvetli akımlar veya drenaj kanallarının tıkanması sonucunda da meydana gelebilir (Gökter, 2006). Ayrıca çok nadir olarak barajların çökmesi ve taşmasından kaynaklanan sellere de rastlanılmaktadır.

Yurdumuzda, doğal vejetasyonun tahribatı, çarpık şehirleşme, sel ve dere yataklarındaki yapılaşmadan dolayı sel ve taşkın olaylarının neden olduğu zararlar artmakta, can ve mal kaybına yol açan afetler daha sık görülmektedir. 1998 yılı Mayıs ayında, Batı Karadeniz'de özellikle Bolu, Zonguldak, Karabük, Kastamonu ve Bartın illerinde meydana gelen sel afetlerinde 2 milyondan fazla kişi etkilenmiş ve 30'dan fazla can kaybı meydana gelmiştir. Yine aynı sel olaylarında bölgedeki irili ufaklı 151 dere ve ırmak yatağı taşmış ve 478 ev tamamen su altında kalmıştır. Bu şekilde geniş alanları kaplayan sel afetleri olduğu gibi, dar alanda etkili olan ani sel olaylarına ait örnekler de ülkemizde çoktur. 3-4 Kasım 1995 tarihlerinde Ege kıyılarını etkisi altına alan şiddetli yağışlar İzmir ve civarında ani taşkınlara sebep olmuş ve bunun sonucunda 61 kişi hayatını kaybetmiş, yüzlerce bina ve yerleşim yeri maddi hasara uğramıştır. (Kömüşcü vd., 1998).

8-12 Eylül 2009 tarihleri arasında İstanbul'da yaşanan sel afeti, 1957 Ankara ve 1995 İzmir sel afetlerinden sonra ülkemizde en fazla can kaybının yaşandığı sel afeti olarak gerçekleşmiştir. Marmara Bölgesi selden ciddi ölçüde etkilenmiş ve afete dönüşen sel olayı 32 can kaybı ile 3816 konut ve 1490 işyerinin zarar görmesine neden olmuştur. Selden en çok zararı dere yataklarının yakınındaki fabrika, otoyol, köprü gibi yapılarla birlikte dere yatağının yakınına kurulan yerleşim yerleri görmüştür (Foto 1).

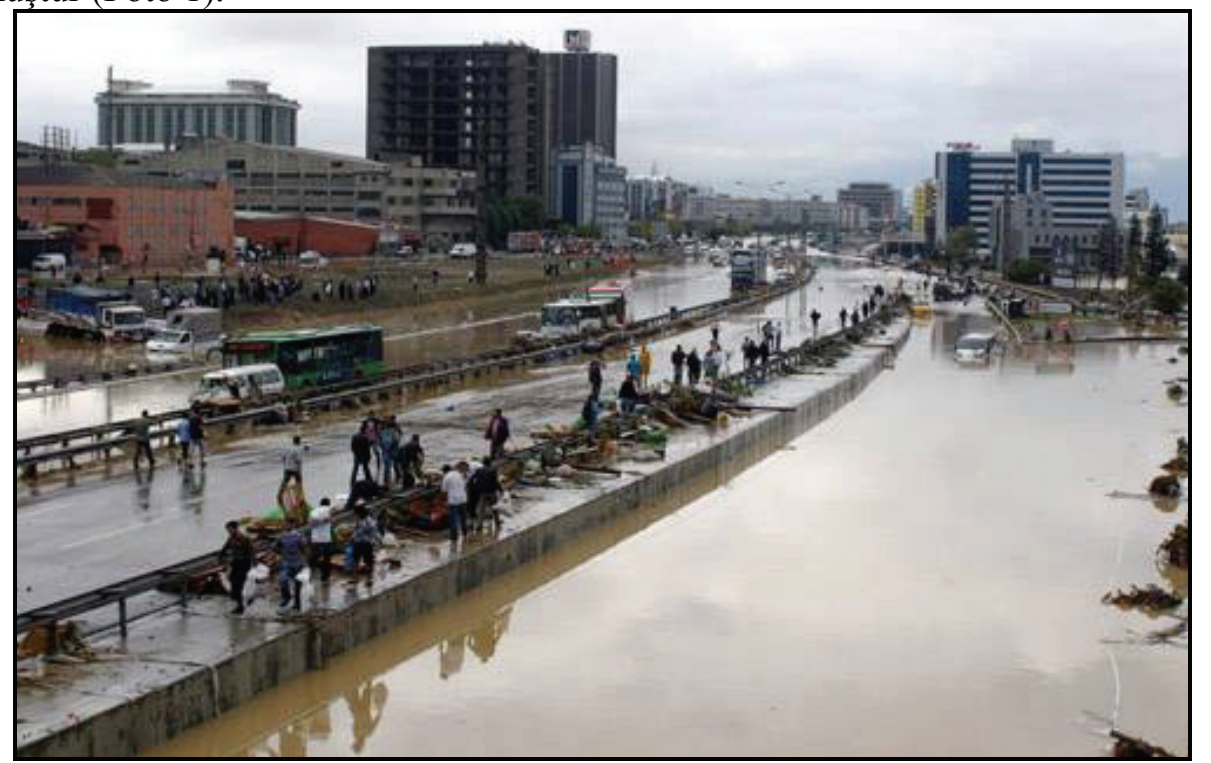

Foto 1. İstanbul'da selin etkilediği alandan bir görüntü: Ayamama Deresi civarı (Kaynak: www.virahaber.com) 
Bu çalışmada, 8-12 Eylül 2009 tarihlerinde Marmara Bölgesi'nde ve özellikle Trakya ve İstanbul'da etkili olan şiddetli yağışların klimatolojik analizi yapılarak, yağış dağılımlarının yer ve zamansal değişimleri ortaya konarak sel afeti ile olan ilişkisi analiz edilmiş̧ir (Şekil 1). Bu bölge Türkiye'nin kuzeybatısında yer almakta olup, Orta Akdeniz ve Balkanlardan gelen cephe sistemlerinin etkisi ile özellikle sonbahar aylarında sık sık şiddetli yağışlara maruz kalmaktadır.

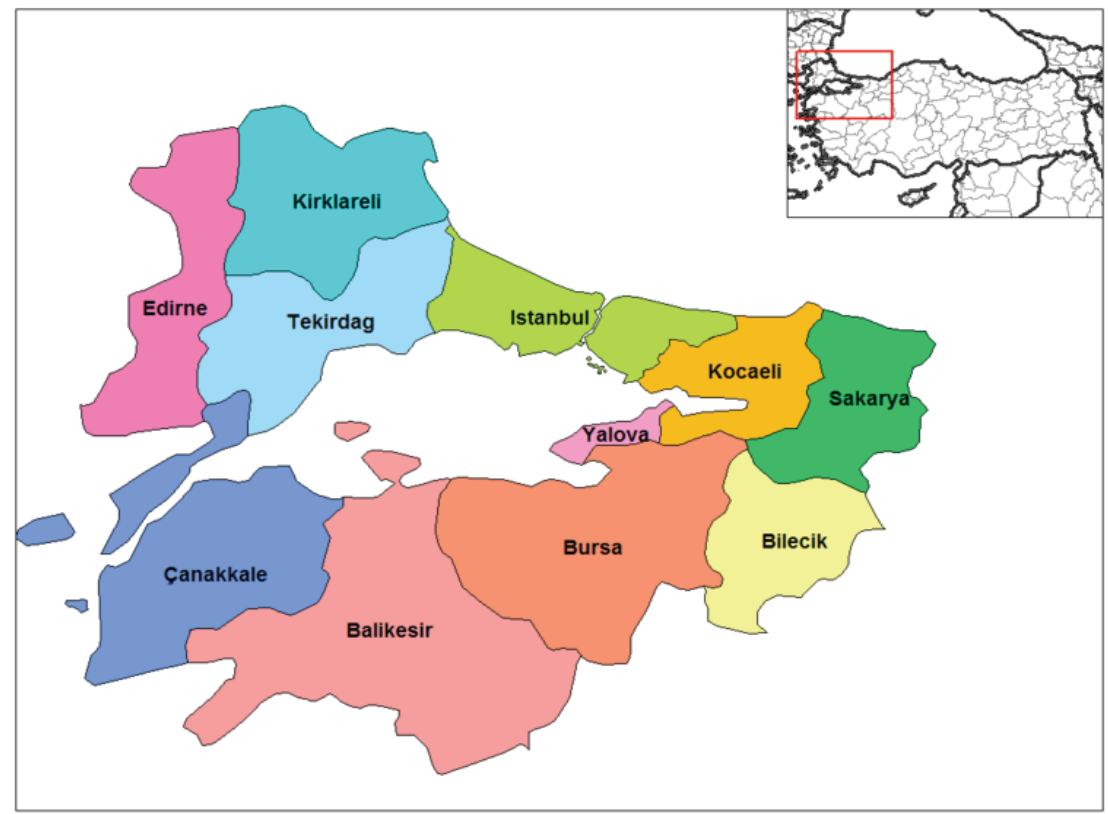

Şekil 1. Marmara Bölgesi’nin Coğrafi Konumu ve İlleri

\section{Meteorolojik ve Klimatolojik Analiz}

\subsection{Yağış Koşulları}

Ülkemizde kıyı kesimlerde meydana gelen sel afetlerine bazı yerel faktörler dışında çoğu kez Karadeniz ve Orta Akdeniz üzerinden gelen siklonlar neden olmaktadır (Çelik ve diğerleri, 2007). Hava kütleleri açısından ele alındığında ise, Türkiye herhangi bir hava kütlesinin kaynak sahası üzerinde olmadığından mevsime göre diğer bölgelerden kaynaklanan hava kütlelerini etkisinde kalmaktadır (Atalay, 2010). Türkiye, yazın tropikal hava kütlelerinin; kışın ise kuzeyden gelen polar hava kütlelerinin etkisi altındadır. Bu hava kütlelerinin kapladığı alan, etki süreleri ve frekansları Türkiye'de yağış ve sıcaklık koşullarının değişmesinde önemli rol oynar. Karadeniz'de görülen şiddetli yağışların oluşumuna bölgenin orografik yapısı katkıda bulunurken, Ege ve Akdeniz sahilinde sıcaklık ve nem koşulları yağış oluşumunda önemli rol oynamaktadır. Buna karşılık Trakya'nın iç kesimleri, İç ve Doğu Anadolu bölgelerinde ise, cephesel yağışların yanında orografik ve lokal konvektif yağışlar da etkili olmaktadır. Ülke genelinde sel olaylarının hem kış hem de ilkbahar ve yaz aylarında görülmesinde, yukarıda belirtilen yağış koşullarının yanısıra şiddetli yağışların ve kar erimelerinin de etkisi vardır. Bunun yanında, ani sıcaklık değişimi, rüzgar ve nem gibi daha birçok meteorolojik parametrenin de sel olaylarının oluşumu üzerinde doğrudan etkisi vardır.

\subsection{Sinoptik Koşullar}

Marmara Bölgesini etkileyen yağışlı sistem 7 Eylül 2009 tarihinden itibaren Türkiye'yi özellikle kuzey batı bölgelerinden itibaren etkilemeye başlamıştır. Burada görülen atmosferik koşullar benzer birçok diğer sel olaylarında görülen sinoptik desene oldukça benzemektedir. $\mathrm{Bu}$ tür sel 
olaylarına ait genel sinoptik deseninde, yüksek seviye haritalarında soğuk hava ve alçak basınç oluğu (trof) uzantısı ile sıcak hava ve sırt arasında kalan alanlarda şiddetli hava olaylarının meydana geldiği gözlemlenmiştir (Pontrelli vd.,1999). 7 Eylül 2009 tarihli yer haritasında Türkiye'nin iç kesimlerinde $1004 \mathrm{hPa}{ }^{\prime} l 1 \mathrm{k}$ alçak basınç merkezi, Orta Avrupa üzerine ise $1026 \mathrm{hPa}{ }^{\prime} l 1 \mathrm{k}$ yüksek basınç merkezi yer aldığ görülmektedir (Şekil 2). Marmara bölgesi üzerinde 1010-1013 hPa'lık izobar değerleri hakim durumdadır. İlerleyen günlerde yüksek basıncın doğu Avrupa'ya doğru genişlemesiyle Balkanlar üzerindeki basınç gradyanı artmış, Marmara bölgesindeki kuzey yönlerden olan rüzgar şiddetlenmiştir. Yine aynı güne ait 500 ve $700 \mathrm{hPa}$ üst atmosfer haritalarında, Ege Denizi üzerinde kuzey-güney istikametinde uzanan trof ve soğuk hava, Marmara bölgesine doğru yaklaştığ görülmektedir (Şekil 2). Bir sonraki gün ise, trof Trakya bölgesine iyice yaklaşmış, soğuk hava ise -15 derece olarak bölge üzerinde etkili olmaya başlamıştır. Ayrıca, yer seviyesinde yüksek basıncın Doğu Avrupa'ya doğru genişlemesiyle Balkanlar üzerindeki basınç gradyanı artmaya devam ederek kuzeyli rüzgârların beraberinde gelen nemli ve soğuk hava bölgeyi etkisi altına almıştır.
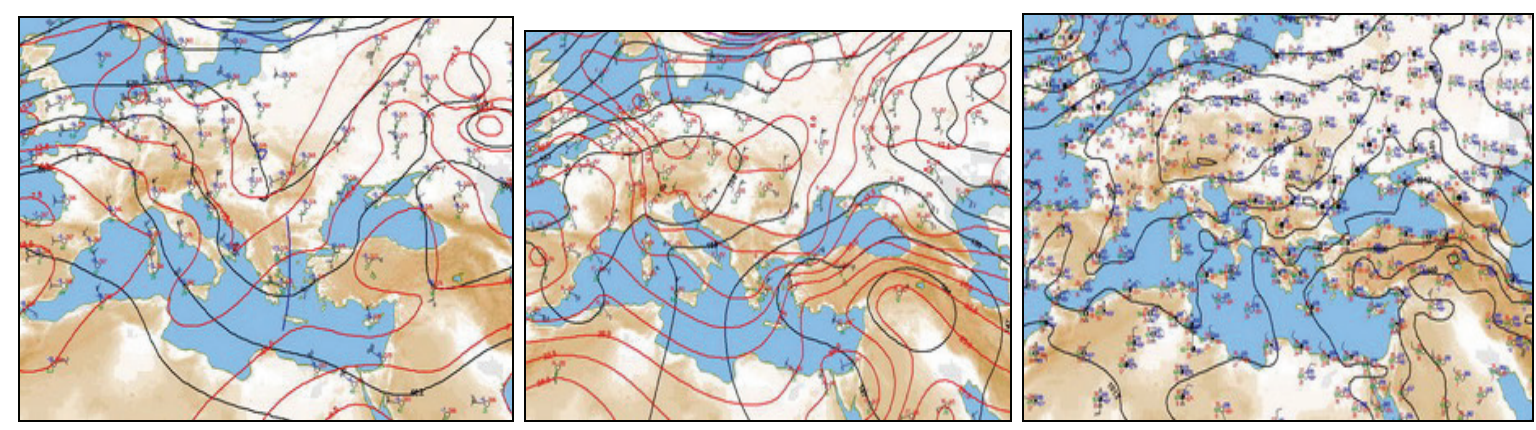

Şekil 2. 7 Eylül 200900 UTC tarihlerine ait 500 hPa (solda), 850 hPa (ortada) ve yer haritası (sağda).

Yağışların devamlılığı sağlayan en önemli etkenlerden biride atmosferin üst seviyelerindeki yüksek nemliliktir (Şekil 3). 9 Eylül 2009 tarihli nisbi nem haritasında görüldüğü üzere İstanbul'un kuzeyinde atmosferdeki nisbi nemlilik \% 100 lere yakın gerçekleşmiştir. Yerdeki sıcak hava ve üst atmosferdeki nemlilik dikey hareketin devamlılığını sağlayarak yağış etkinliğini artırmıştır.

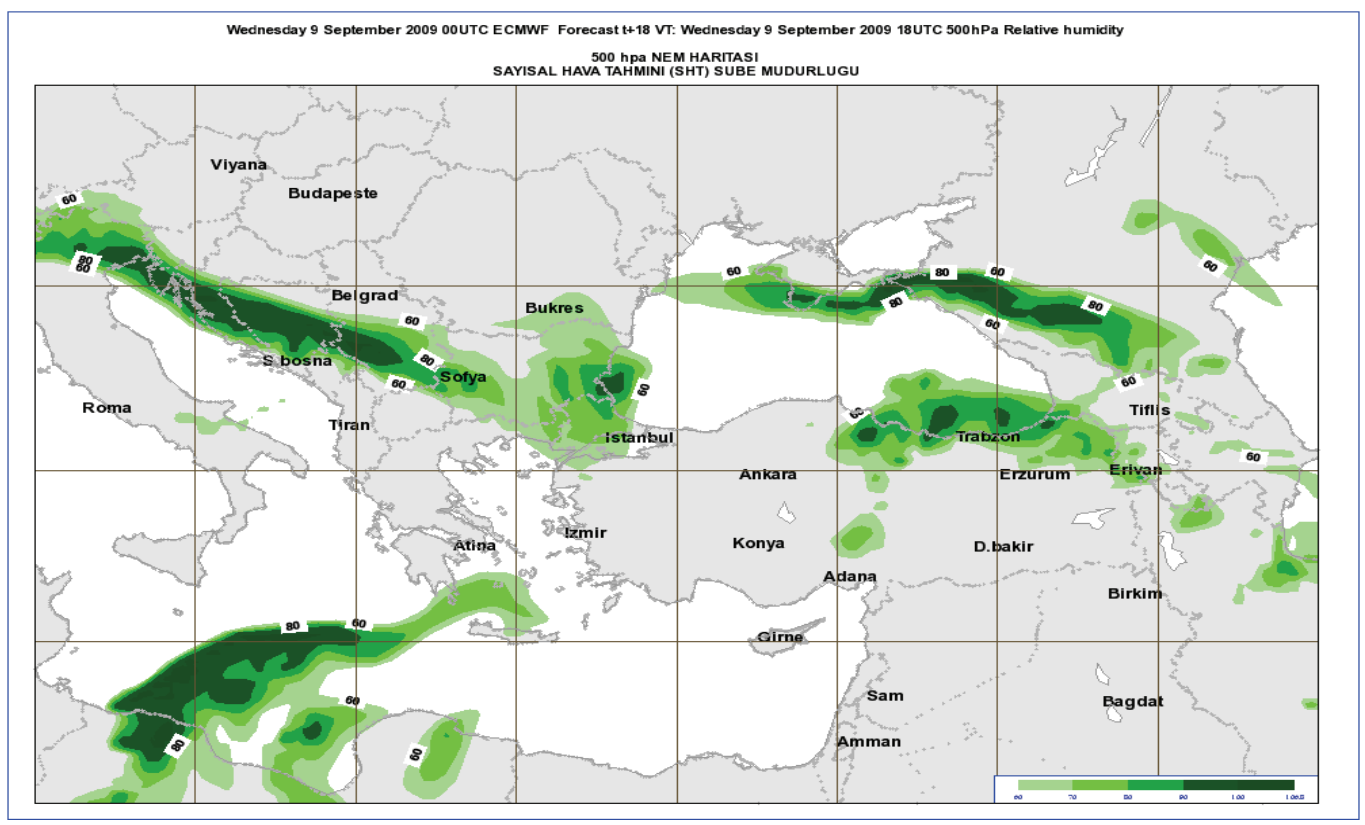

Şekil 3. 9 Eylül 200900 GMT 500 mb Nisbi Nem (Kaynak: ECMWF) 
Avrupa Orta Vadeli Tahmin Merkezi, ECMWF'den (European Centre for Medium-Range Weather Forecasts) alınan sayısal hava tahmin ürünlerinden olan dikey hız diyagramında ise Marmara bölgesi ve yağışın gözlendiği alanlardaki konvektif faaliyetlerin gelişimi görülmektedir (Şekil 4). Buna göre özellikle Marmara Bölgesi üzerinde dikey yükselme hızında artış olduğu ve bununda konvektif faaliyetlere zemin hazırladı̆̆ı ortaya çıkmaktadır.

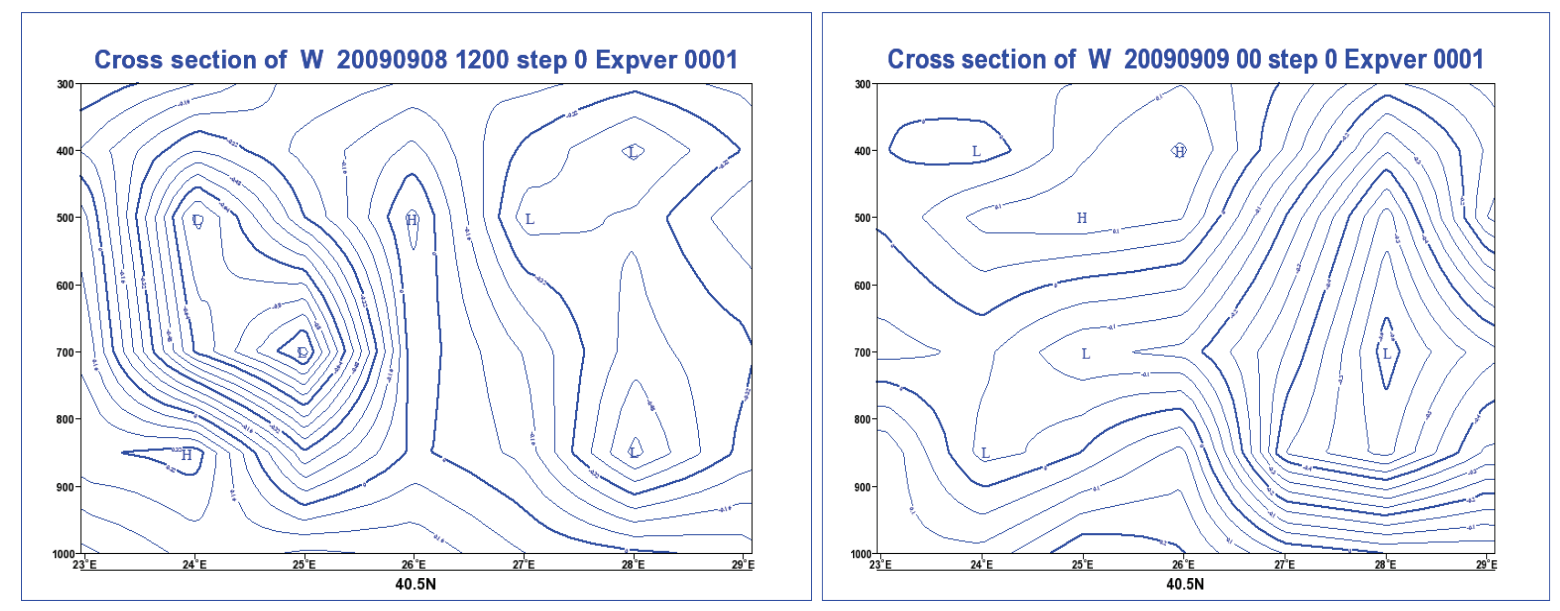

Şekil 4. 08 Eylül 2009 12:00UTC ve 9 Eylül 2009 00:UTC tarihlerine ait ECMWF den alınan(Selanik-İstanbul) dikey yükselme hızını (vertical velocity $\mathrm{Pa} / \mathrm{sn}$ ) gösteren analizler

$\mathrm{Bu}$ çalışmanın esas amacı sel olayın meteorolojik boyutunu detaylı incelemek olmadığından şiddetli yağışa zemin oluşturan atmosferik koşullara kısaca değinilmiştir.

\subsection{Yağış Analizi}

Çalıșmanın bu bölümündeki Meteoroloji Genel Müdürlüğü tarafindan Marmara Bölgesi’nde işletilen Otomatik Gözlem İstasyonları (AWOS), klimatoloji ve sinoptik istasyonların verilerine dayanarak bazı analizler yapılmıştır. Bu analizlere göre, yağışlar 7 Eylül 2009 tarihinde Trakya bölgesinde başlamış ve 8 Eylül 2009 tarihinde ise afet bölgesini de içine alacak şekilde artarak devam etmiştir (Şekil 5). 7 Eylül 2009 tarihinde son 24-saatlik toplam yağışlara bakıldığında yağışın Kırklareli civarında yoğunlaştığı göze çarpmaktadır. 8 Eylül 2009 tarihi öğle saatlerinden itibaren etkisini arttırmaya başlayan yağışlar, 9 Eylül 2009 tarihinde sabah saatlerine kadar devam etmiş ve bölgede büyük bir afete neden olmuştur. 8 ve 9 Eylül tarihlerini içine alacak şekilde 48 ve 72 saatlik yağış toplamları incelendiğinde yağışın merkezinin Çatalca ve İstanbul'un Avrupa yakasında kalan bölgeler olduğu görülmektedir. Bölgede kaydedilen 24 saatlik yağış miktarları 100-250 mm arasında olmak üzere oldukça yüksek değerlere ulaşmıştır. En yüksek yağış miktarı Bandırma'da $253 \mathrm{~mm}$, Çatalca'da $205 \mathrm{~mm}$, Erdek'te $170 \mathrm{~mm}$, Silivri'de $128 \mathrm{~mm}$, Sarıyer'de $107 \mathrm{~mm}$ ve Tekirdağ'da 103 mm olarak gözlemlenmiştir. Yağışın etkinliği 9 Eylül tarihinde en üst düzeye ulaşmış ve bu tarihten itibaren yağış etkinliğini kaybetmeye başlamıştır. 


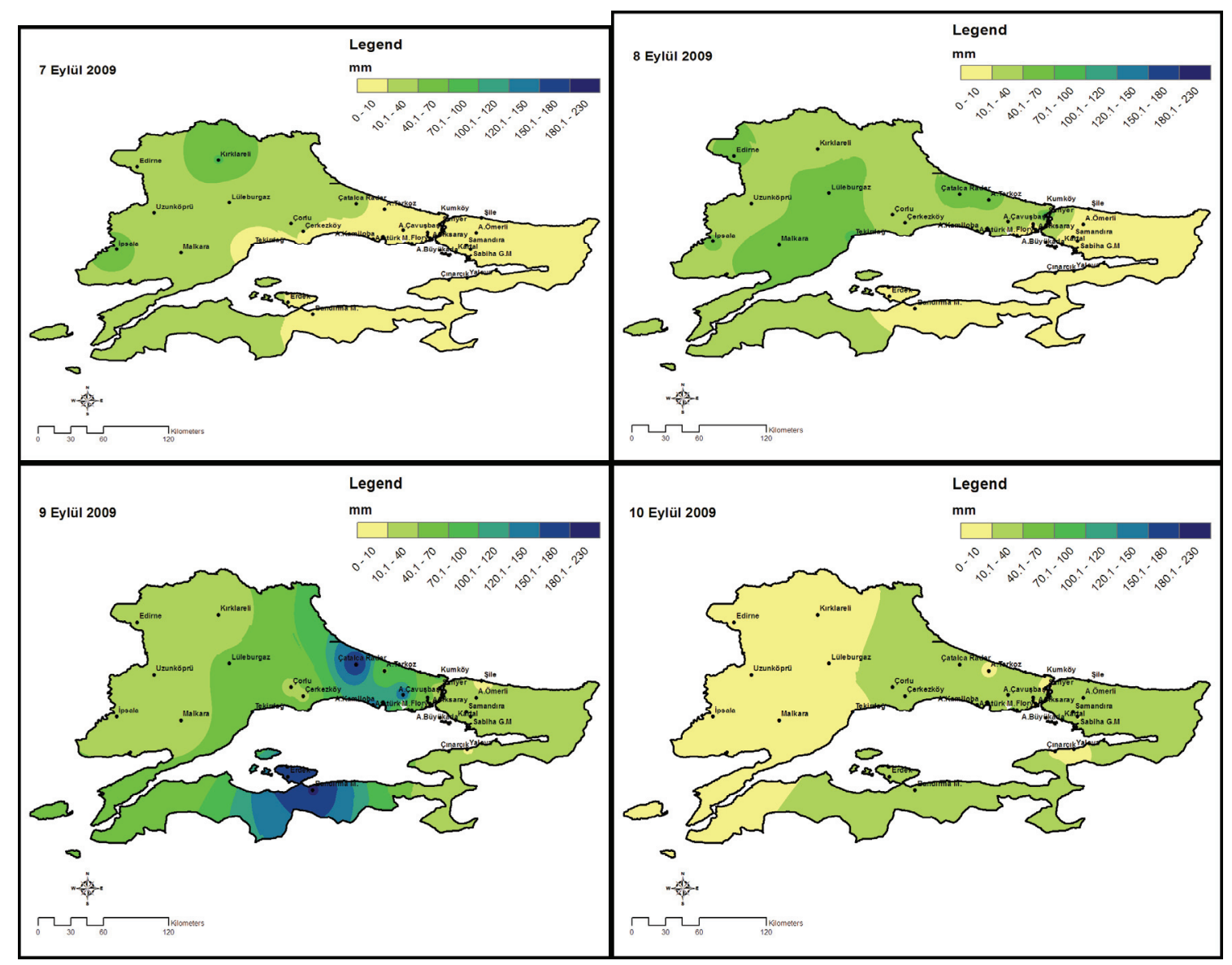

Şekil 5. Marmara Bölgesinde 7-10 Eylül 2009 tarihleri arasında günlük toplam yağışların dağılımı

07-10 Eylül 2009 tarihleri arasındaki 4 günlük yağış değerlendirmesi dikkate alındığında, bu dönem için Marmara Bölgesi yağış ortalaması 74,1 mm olarak gerçekleşmiştir. Uzun yıllar eylül ayı bölge yağış ortalaması ise $36,3 \mathrm{~mm}$ 'dir. Buna göre 4 günlük dönemde bölge geneli yağış ortalaması eylül ayı yağışının 2 katından daha fazladır. Çizelge-1 ve Şekil 6'de görüldüğü gibi 4 günlük yağ1Ş toplamı bazı merkezlerde uzun yıllar eylül ayı ortalama yağışının 8 katından fazla olarak kaydedilmiştir. Yağış şiddet çizelgesinde görüldüğü üzere 8 ve 9 Eylül 2009 tarihlerinde Bandırma, Çatalca ve Gönen istasyonlarında kaydedilen yağış değerleri bu istasyonlarda şimdiye kadar kaydedilen en büyük yağış değerleridir. Bu yağışların tekerrür periyodları 100 yıldan fazladır.

Çizelge-1. Bazı istasyonlara ait yağış-şiddet analizi

\begin{tabular}{|c|c|c|c|c|c|c|c|}
\hline İSTASYON & Tarih & Başlama & Bitiş & Süre & Miktar & $\begin{array}{c}\text { Tekerrür } \\
\text { Periyodu (yll) }\end{array}$ & Açıklama \\
\hline BANDIRMA & 08.09.2009 & $14: 20$ & $16: 20$ & 2 Saat & 82,2 & $>100 \mathrm{Y} 1$ & 2 saatlik periyotta en yüksek yağı̧ (1991 Yılında 73,9 mm) \\
\hline BANDIRMA & 09.09.2009 & 04:20 & 08:20 & 4 Saat & 125,0 & $>100$ Yil & 4 saatlik periyotta en yüksek yağıș (1991 Yılında 124,4 mm) \\
\hline ÇATALCA & 08.09.2009 & $12: 30$ & $15: 30$ & 3 Saat & 134,4 & $>100$ Yil & 3 saatlik periyotta en yüksek yağı̧ (1972 Yılında 62,4mm) \\
\hline ÇATALCA & 08.09 .2009 & 07:30 & $15: 30$ & 8 Saat & 166,8 & $>100$ Yil & 8 saatlik periyotta en yüksek yağı̧ (1997 Yılında 104,4mm) \\
\hline GONEN & 08.09.2009 & 08:10 & 11:10 & 3 Saat & 83,8 & $>100 \mathrm{Y}_{1} 1$ & 3 saatlik periyotta en yüksek yağış (1979 Y1lında 62,1mm) \\
\hline
\end{tabular}




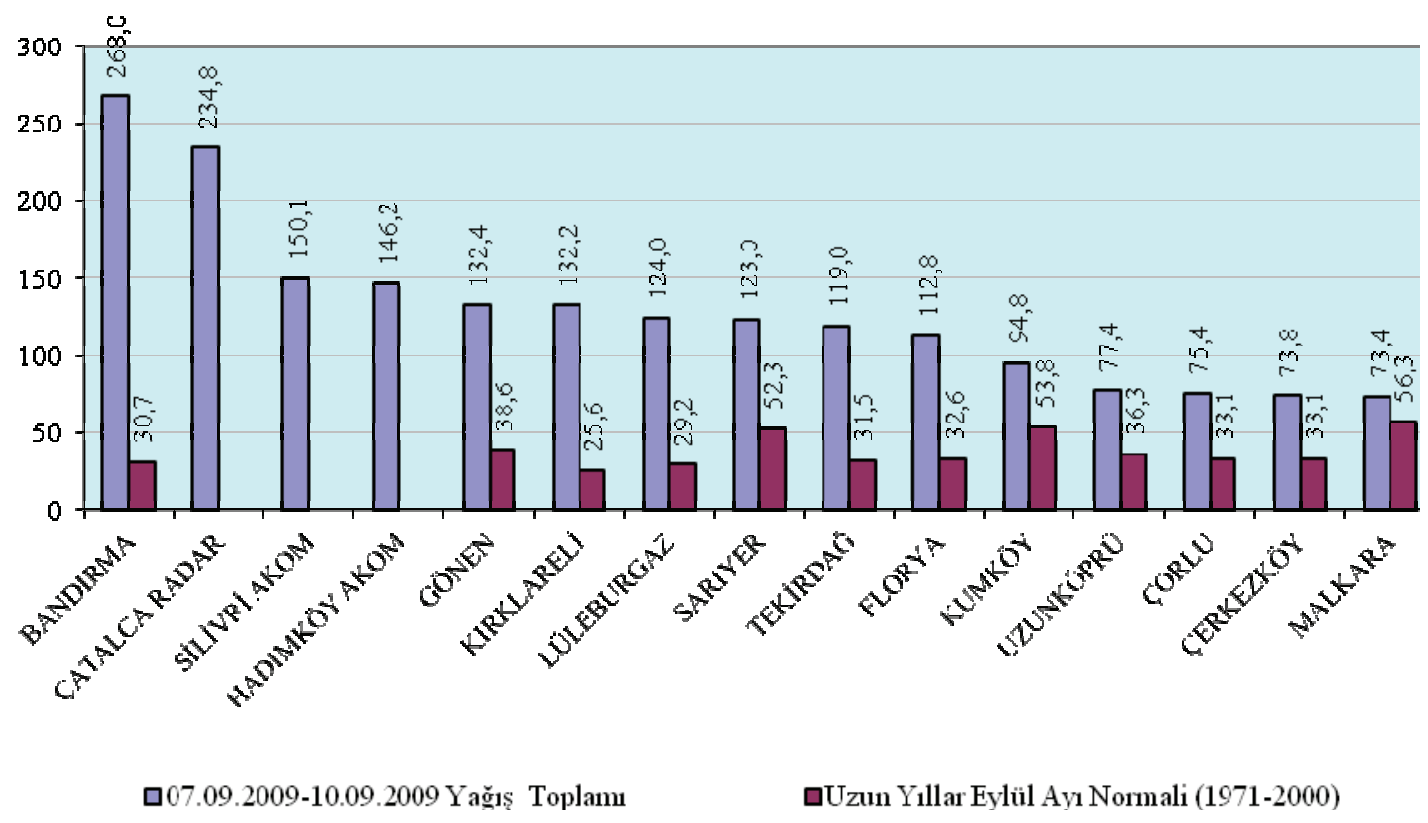

Şekil 6. 07.09.2009- 10.09.2009 (4 Günlük) Toplam Yağış Miktarları (mm)

24 saatlik toplam yağışlara göre, İpsala-Sarıyer arasındaki istasyonlar batıdan doğuya doğru enleme göre sıralandığında, Tekirdağ Florya arasında kalan alanın belirgin bir şekilde fazla yağış aldığı görülmektedir (Şekil 7). Çatalca ve Silivri ilçelerini de kapsayan bu alan, sel afetinden en fazla etkilenen bölge olmuştur.

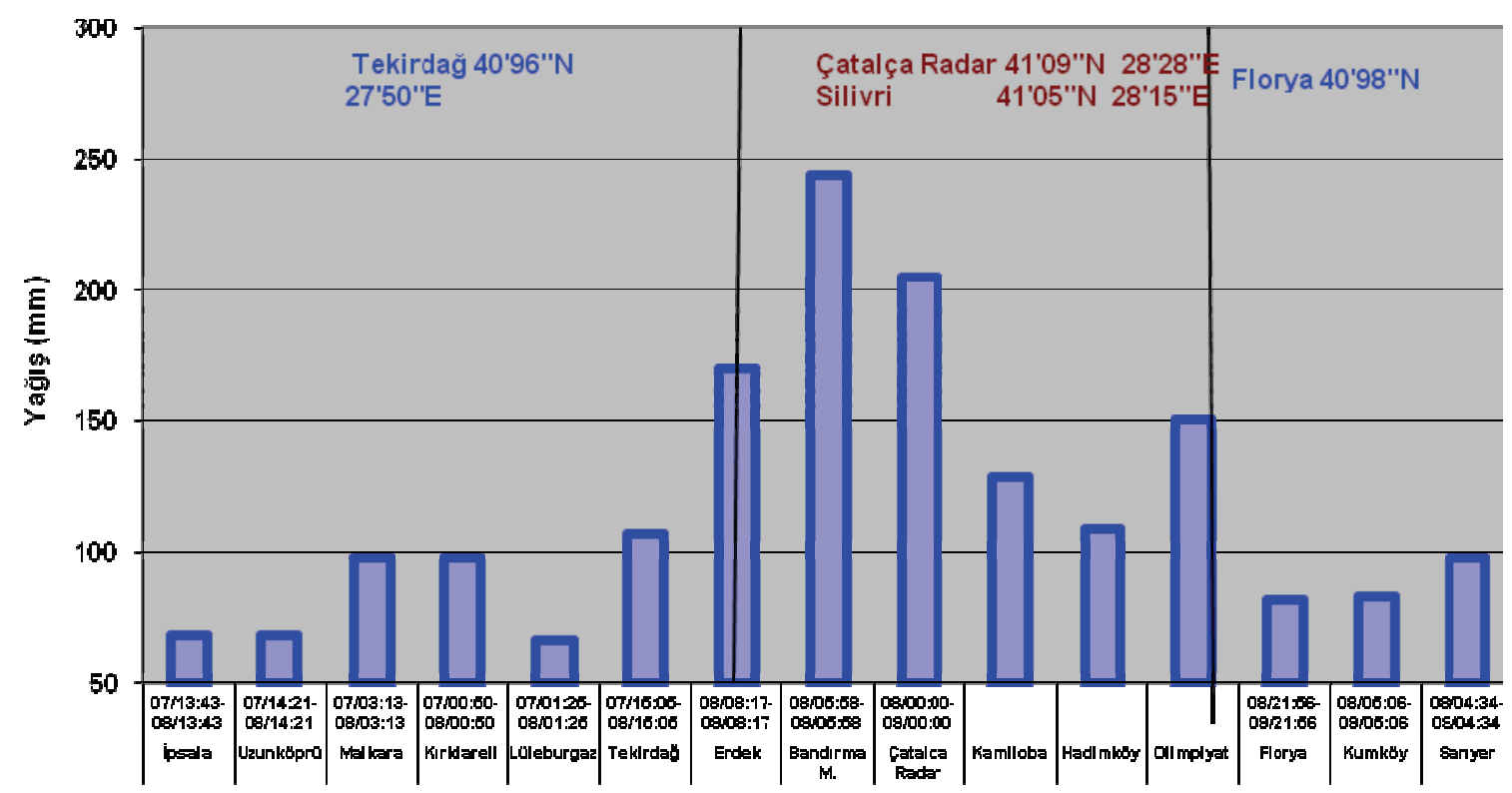

Batı-Doğu Yönüinde yerleșim yerleri

Şekil 7. Marmara bölgesinde 24 saatte en fazla yağış alan merkezlerin B-D doğrultusunda sıralanış1 


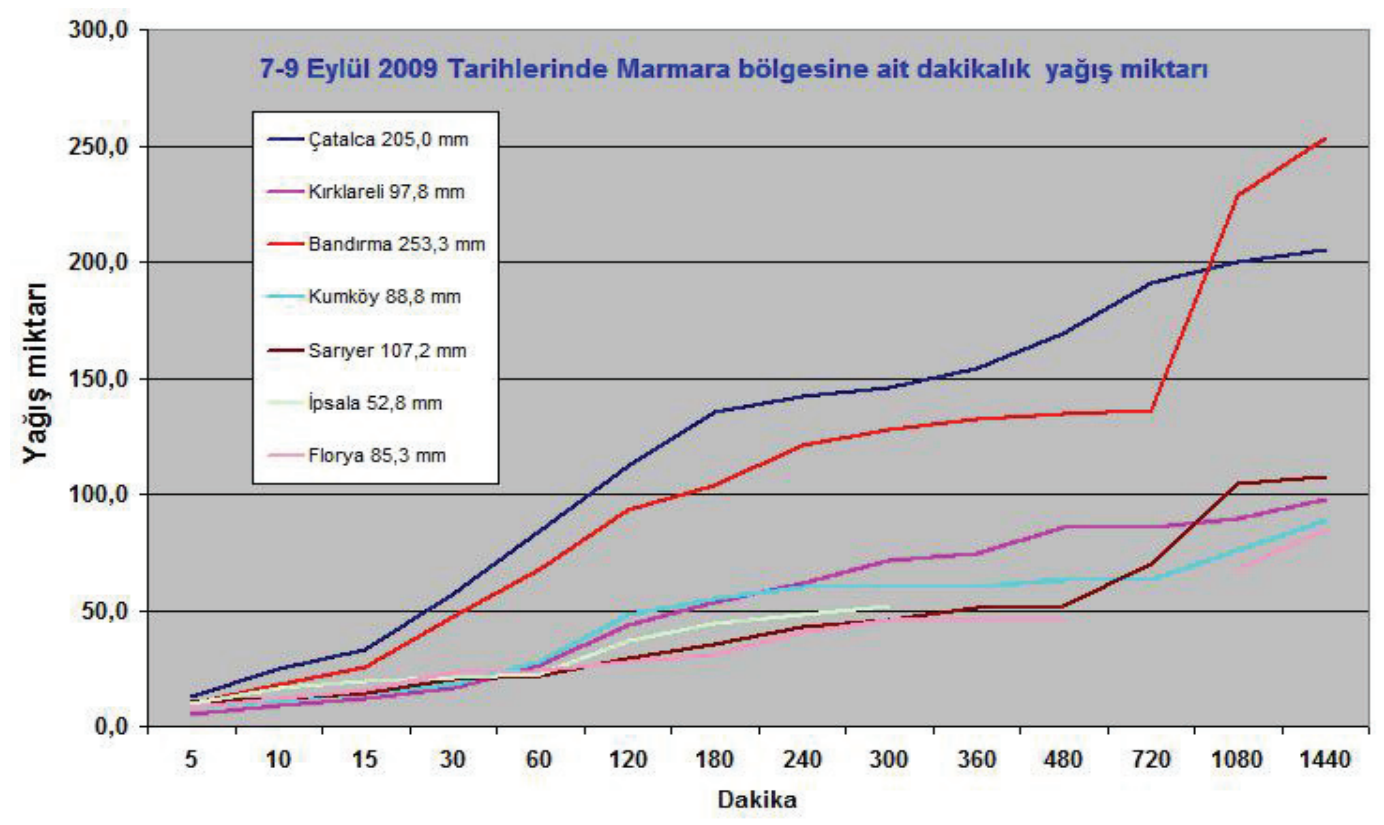

Şekil 8. Standart sürelere ait dakikalık şiddetli yağış analizi (Bandırma, Florya, Kumköy ve Sarıyer istasyonlarında plüviograf analiz dataları kullanılmıştır)

Afet bölgesine düşen yağış değerleri klimatolojik açıdan ekstrem değerlerdir. Bir saat içerisinde düşen yağış miktarının 50 mm' nin üzerinde olduğu (Bandırma, Çatalca ve Erdek istasyonları) istasyonlar aynı zamanda sel afetinden etkilenen yerleri göstermektedir. İstanbul'un uzun yıllar 24 saatlik ekstrem yağışı, istasyonlara göre değişmekle birlikte 130-184 mm arasındadır. Ancak, bu iki günlük sürede bazı istasyonlarda $200 \mathrm{~mm}$ ' nin üzerinde yağış gerçekleşmiştir (Şekil 8). Toplamda ise Marmara Bölgesi genelinde 4 günlük yağış toplamları maksimum $230 \mathrm{~mm}$ civarında ölçülmüsştür (Şekil 9).

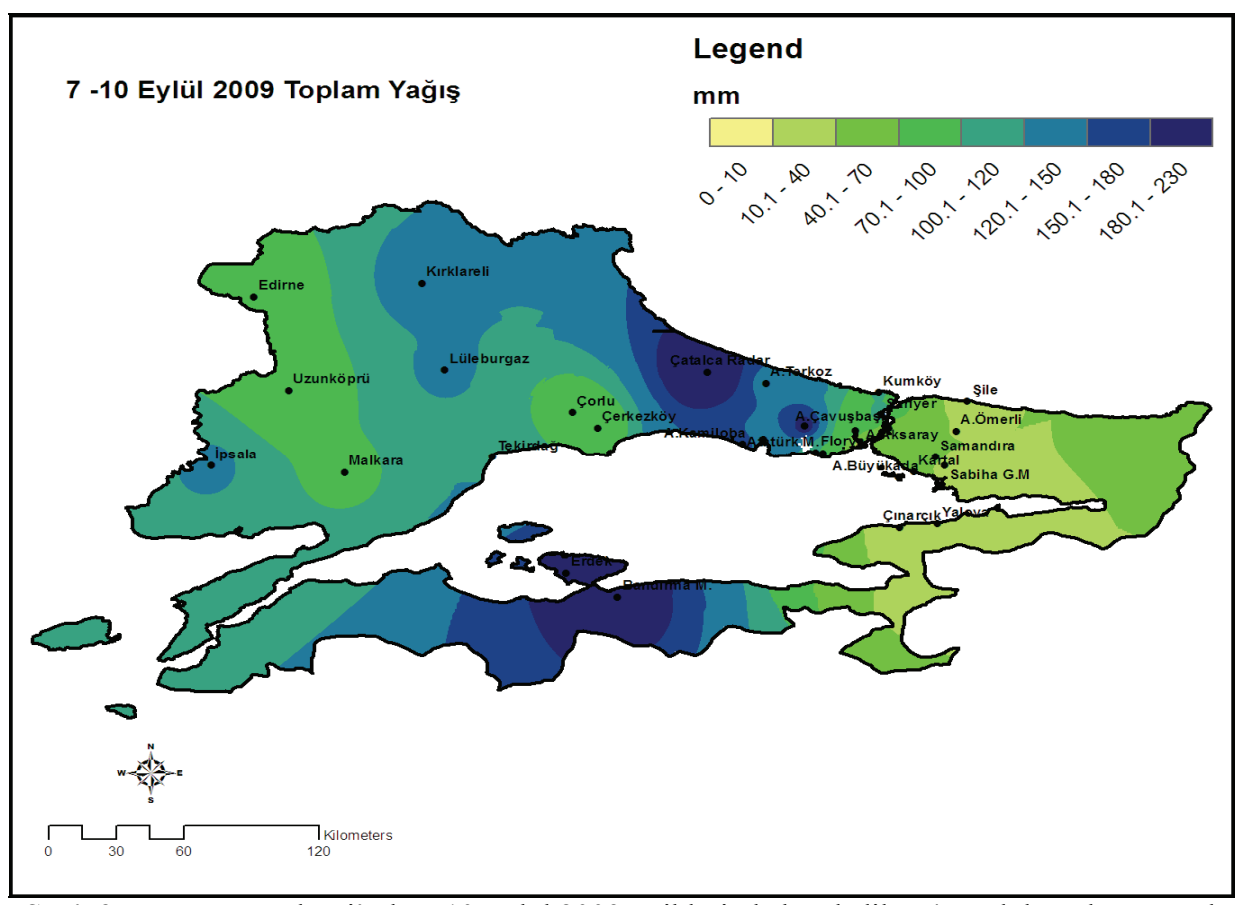

Şekil 9. Marmara Bölgesi’nde 7-10 Eylül 2009 tarihlerinde kaydedilen 4-günlük toplam yağışlar 


\subsection{Kararsızlık İndisleri Analizi}

Şiddetli hava, yoğun yağış ve konveksiyon olaylarının tespitine yönelik olarak havadaki nem ve atmosferik koşulların kararsızlığının değerlendirilmesi oldukça önemlidir. Nem değerlendirilmesinde, yüzey ve $700 \mathrm{mb}$ işba sıcaklıkları kullanıldığı gibi yağışa dönüşebilir su (PW), $\mathrm{K}$, TOTAL TOTALS (TT), CAPE, SWEAT ve Lifted kararsızlık indis değerleri de dikkate alınmaktadır (DMİ, 2007). Bu indislere ait eşik değerleri birbirine göre farklılık göstermektedir. 7-9 Eylül 2009 tarihinde Marmara bölgesinde kuvvetli yağış oluşumunu destekleyen kararsızlık parametreleri arasında sıcaklık ve rüzgarın öne çıktı̆̆ görülmektedir. Kararsızlık indislerinin çoğunda temel değişkenler sıcaklık ve nem parametreleridir. Marmara bölgesi yağış öncesi günlerde $30^{\circ} \mathrm{C}$ 'ye varan sıcaklık ve $20-22{ }^{\circ} \mathrm{C}$ 'ye yükselen işba sıcaklığı bölgedeki nemliliği artırmıştır.

Özellikle yağışın bölgede etkili olduğu 7-8 Eylül 2009 tarihlerindeki 00 UTC saatindeki Kararsızlık indislerinden SWEAT, K ve TT indislerinin sınır değerlerinde olduğu Çizelge-2'den anlaşılmaktadır. Hemen hemen tüm indis değerleri belirlenen marjinal sınırların üzerindedir. Özellikle $\mathrm{K}$ indis değerindeki artış oldukça belirgindir ve Maddox (1979) tarafından belirlenen 30 sınırının oldukça üstündedir. SWEAT İndeks değerlerinin çok yüksek çıkması da yer ve yüksek seviye rüzgarlarının oldukça farklı yönlerden estiğinin bir göstergesidir. Yüzey ile $500 \mathrm{hPa}$ seviye arasındaki PW (precitable water) değeri 31.4'e ulaşarak Doswell (1982) tarafından belirlenen şiddetli yağış sinırını aşmaktadır.

Çizelge 2. 6-11 Eylül 2009 tarihleri arasında İstanbul için radyosonde ölçümlerinden elde edilen 00 UTC kararsızlık indis değerleri

\begin{tabular}{lccccccc}
\hline & 06.Eyl.09 & 07.Eyl.09 & 08.Eyl.09 & 09.Eyl.09 & 10.Eyl.09 & 11.Eyl.09 & $\begin{array}{c}\text { Eşik } \\
\text { Değerleri }\end{array}$ \\
\hline Lifted & 7,44 & $-0,48$ & $-3,12$ & $-1,48$ & $-1,03$ & $-0,13$ & -3 \\
\hline SWEAT & 51,40 & 185,20 & 185,60 & 162,80 & 156,30 & 164,20 & 300 \\
\hline CAPE & 0,00 & 62,59 & 720,80 & 526,10 & 325,10 & 147,50 & $\leq 1000$ \\
\hline TT & 41,20 & 45,40 & 49,30 & 46,50 & 47,40 & 44,70 & $>48$ \\
\hline K & 14,30 & 15,50 & 32,40 & 32,30 & 34,90 & 30,10 & $>30$ \\
\hline PW (mm) & 19,27 & 30,95 & 38,97 & 37,57 & 41,92 & 37,40 & -
\end{tabular}

Yağış periyodunda 35-40 değerleri arasında değişen PW değerleri şiddetli yağışlar için gerekli nemliliğin varlığını göstermektedir (Şekil 10). Yüksek PW değerleri özellikle Marmara Bölgesi üzerinde yoğunlaşmaktadır.

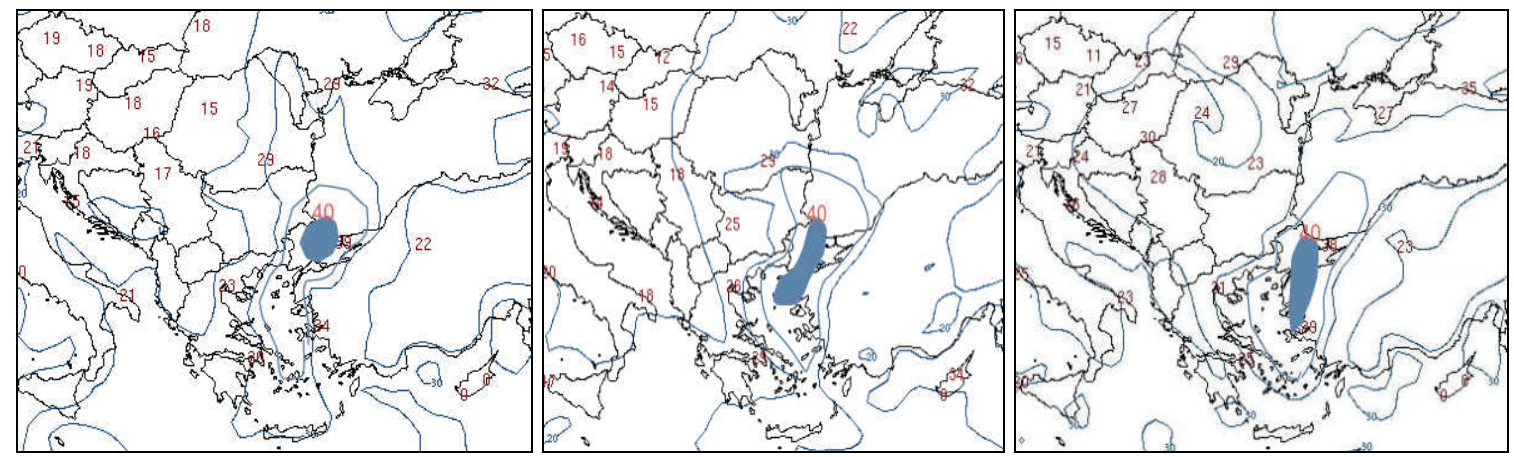

Şekil 10. 8 Eylül 200900 (sol) ve 12 (orta) ile 09 Eylül 200900 (sağ) UTC de PW değerlerinin afet bölgesi üzerinde en yüksek değerlerde olduğu görülmektedir. 


\subsection{Uydu ve Radar Görüntüleri Analizi}

8-12 Eylül 2009 tarihlerinde Trakya ve özellikle İstanbul ve civarında meydana gelen sel afetine zemin hazırlayan şiddetli yağışlar uydu ve radar görüntülerinde de açıkta görülmektedir. DMI tarafından işletilen İstanbul radarından alınan görüntülerde 7-8-9-10 Eylül günlerine ait yağış oranları $(\mathrm{mm} / \mathrm{saat})$ gösterilmektedir (Şekil 11). Bu görüntülerden de anlaşılacağı üzere şiddetli yağışların 7-8-9 Eylül tarihlerinde etkili olduğu görülmekte ve 9 Eylül'den sonra ise sistemlerin zayıflayarak yağışın bölgeyi terk ettiği gözlenmektedir.

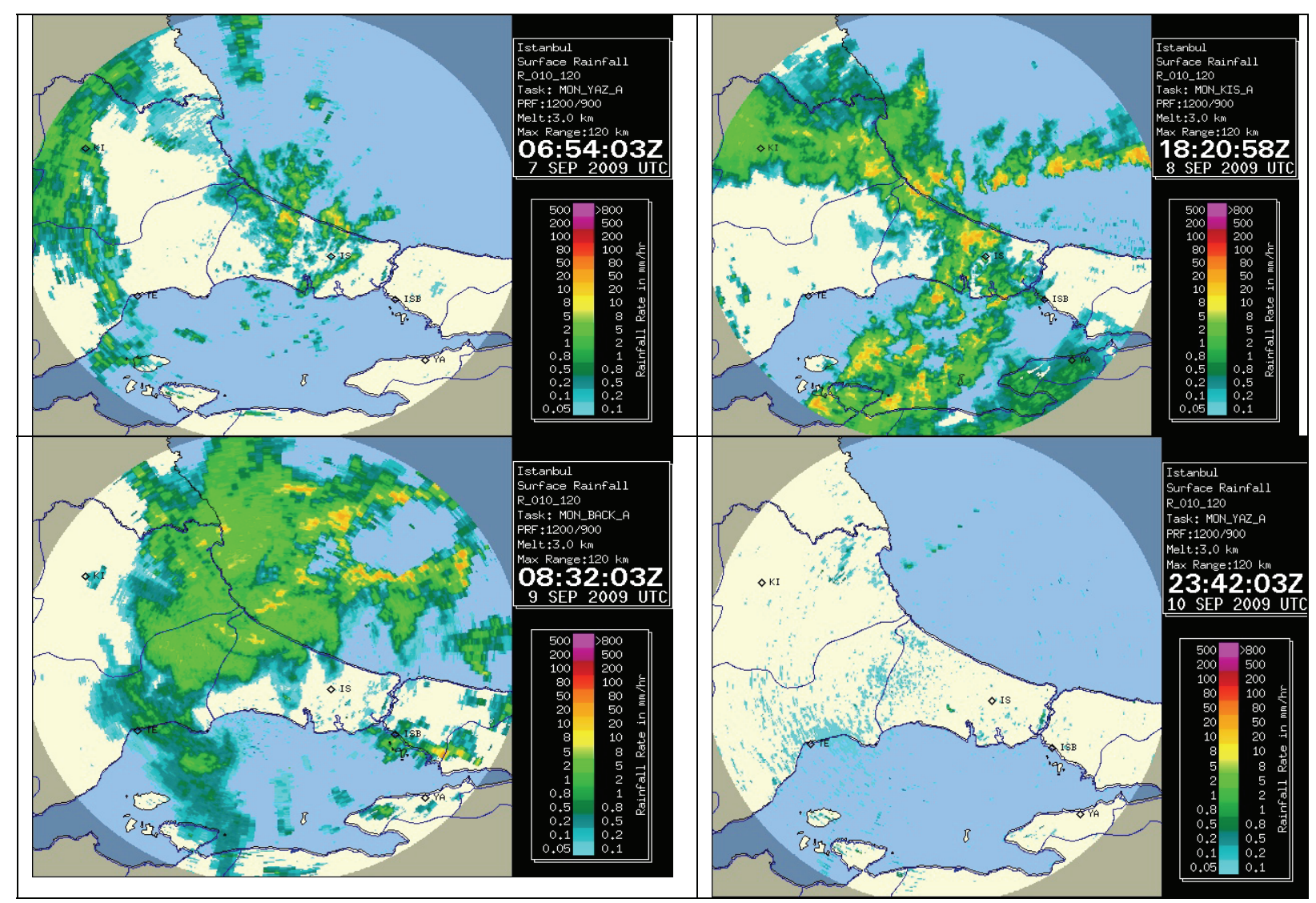

Şekil 11. 7-8-9-10 Eylül günlerine ait radar verilerinden elde edilen yağış oranları $(\mathrm{mm} / \mathrm{saat})$

7-8-9-10 Eylül günlerinde Marmara Bölgesi'ni etkileyen şiddetli yağışların etkinliği EEMETSAT 2.Nesil Uydu (MSG) görüntülerinden de anlaşılmaktadır (Şekil 12). Aşağıdaki şekilde bu 4 güne ait infrared (kızılötesi) kanaldan elde edilen ve bulutla kaplı alanları gösteren uydu görüntüleri verilmektedir. Şekilden, 7 Eylül'de KD-GB akışlı sistemin Balkanlar üzerinden Marmara Bölgesi’ne girdiği ve özellikle 8-9 Eylül tarihlerinde tüm Marmara Bölgesi’ni kapsadığg ve 10 Eylül tarihinde ise yağışların oldukça azaldığı görülmektedir. 


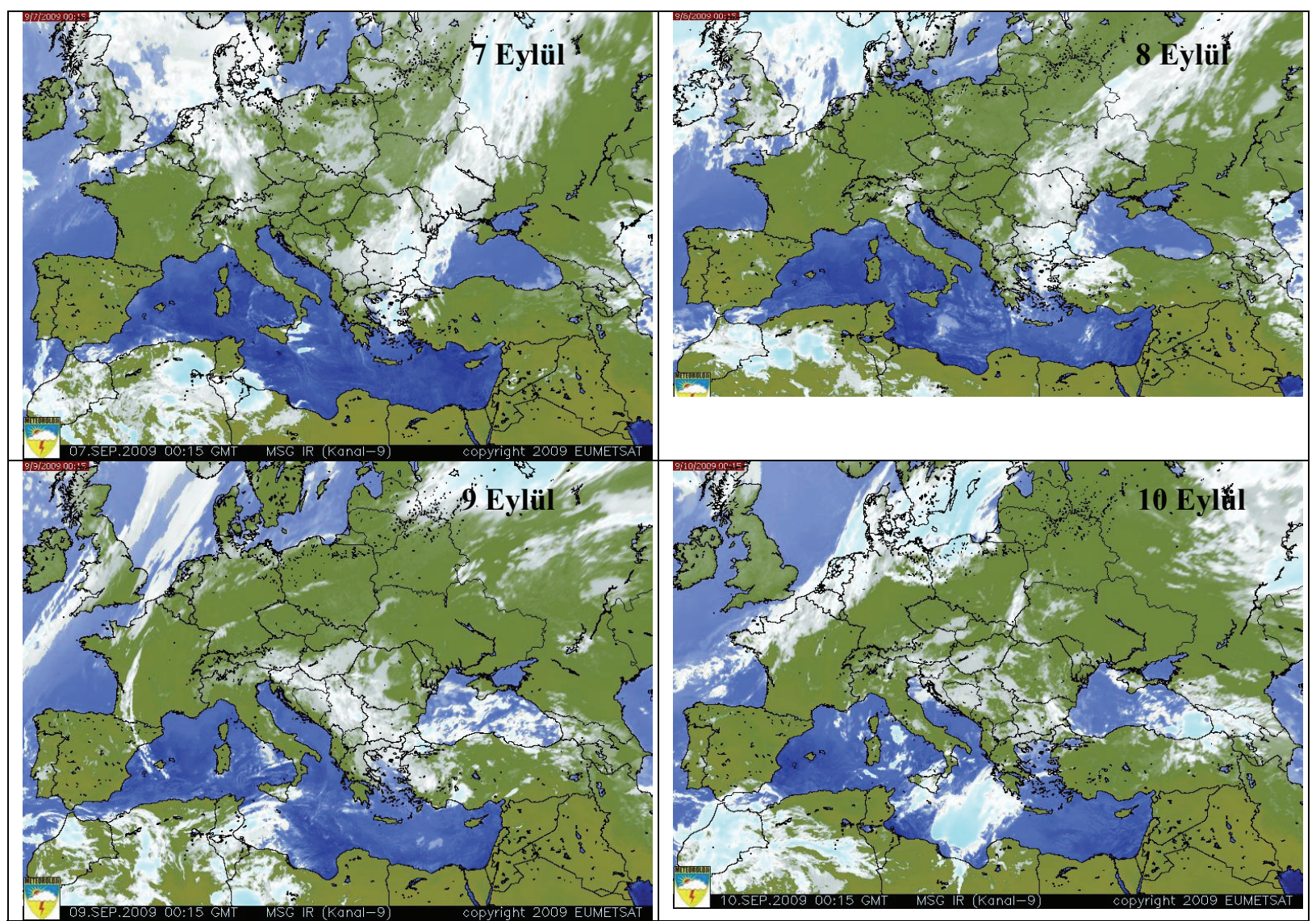

Şekil 12. 7-8-9-10 Eylül günlerine ait infrared (kızılötesi) kanal MSG uydu görüntüleri

\section{Sonuç ve Öneriler}

Bu çalışmada, 8-12 Eylül 2009 tarihlerinde Türkiye'nin Trakya bölgesinde ve özellikle Tekirdağ ve İstanbul' un batı kesimlerinde etkili olan şiddetli yağışlar analiz edilmiştir. Bölgede yağışlar 7 Eylül 2009 tarihinde Trakya bölgesinde başlamış ve 8 Eylül 2009 tarihinde ise afet bölgesini de içine alacak şekilde artarak devam etmiştir. Uydu ve radar verileri de özellikle 7-9 Eylül tarihlerinde bölgede etkili olan şiddetli yağışların varlığını kanıtlamaktadır. Sonuç itibarı ile, 8 Eylül'de Trakya'da 9 Eylül'de İstanbul'da ve takip eden günlerde ise Marmara'nın güney bölgelerinde oluşan şiddetli yağışlar sel afetlerinin yaşanmasına neden olmuştur. Bandırma ilçesinde rasat süresi boyunca, 24 saatlik en yüksek yağış miktarı 1991 yılında 178,8 mm olarak ölçülmüştür. 9 Eylül 2009 sabahı ise $253.3 \mathrm{~mm}$ (ekstrem yağışın oldukça üzerinde) yağış kaydedilmiştir. Çatalca $(205 \mathrm{~mm})$ ve Silivri'de meydana gelen şiddetli yağışlarda diğer merkezlerle kıyaslandığında ekstrem olarak görülmektedir. 8 Eylül 2009 sabahı kaydedilen yağış miktarı, Kırklareli’nde ekstrem değere $(97,8$ $\mathrm{mm}$ ) ulaşırken Tekirdağ' da ise 25-50 y1lda bir görülebilecek büyüklükte (103,2 mm) ölçülmüsstür.

Bandırma, Erdek, Çatalca ve Silivri istasyonları arasında kalan alanda bu kadar büyüklükte yă̆ış bırakan sistemin oluşumu ve gelişimi iki ayrı nokta üzerinde ve farklı zamanlarda meydana gelmiştir. Yağış analizleri, uydu ve radar görüntülerinin verdikleri sonuçlara göre hem 8 Eylül 2009 10:00 UTC, hem de 9 Eylül 2009 03:00 UTC' de sel oluşturabilecek (saatte $50 \mathrm{~mm}$ ) büyüklüğün üzerinde yağış kaydedilmiştir. 
Akdeniz iklim kuşağında yer alan ülkemizde meteorolojik kaynaklı doğal afetlerin kıyı kesimler başta olmak üzere ülkenin büyük bölümünde özellikle ilkbahar ve sonbahar aylarında gerçekleşme ihtimali yıl boyunca mevcuttur. Bunun en önemli nedeni şiddetli yağışların oluşumuna zemin hazırlayan atmosferik kararsızlık koşullarıdır. Deniz ve kara yüzeyleri arasındaki farklı ısınmanın ve orografinin getirdiği yağış oluşumunu destekleyici yan etkilerde bulunmaktadır. Ayrıca tropik ve polar hava kütleleri ve jet eksenleri Türkiye'nin bulunduğu enlemler üzerinde daha fazla birbirine yaklaşarak meteorolojik olayların şiddetini arttırmaktadır.

Sonuç olarak belirtilmesi gereken diğer bir husus ise, bu çalışmada Marmara Bölgesi'nde meydana gelen sel olayı sadece yağış klimatolojisi açısından analiz edilmiştir. Yağışın yere düştükten sonra geçirdikleri aşamalar ve bunun bir afetine dönüşmesi sadece şiddetli yağış ve buna zemin hazırlayan atmosferik koşullar ile açıklanamaz. Bu durumda, özellikle İstanbul gibi metropoller için başta jeomorfolojik ve fizyografik koşullar olmak üzere, arazi kullanımı, plansız şehirleşme, taşkın yataklarındaki yapılaşmalar ve diğer altyapı ve sosyo-ekonomik faktörleri de ele alarak sel afetini analiz etmek daha doğru bir yaklaşım olacaktır. İstanbul'da gerek bu sel esnasında ve gerekse önceki sel afetleri esnasında yaşanan can ve mal kayıpları özellikle yanlış arazi kullanımı ve şehirleşme faktörlerini ön plana çıkarmaktadır. İstanbul'un uzun yıllardır göç aldığı ve bu nedenle de çarpık yapılaşmaya maruz kaldığı bilinen bir gerçektir. Ayamama ve Kağıthane gibi derelerin taşkın yataklarına yerleşim, bu alanlara konut ve fabrika yapımı, dere 1slah çalışmalarındaki yetersizlikler, doğal drenajın bozulması gibi faktörler sel olaylarını kısa sürede afete dönüştürebilmektedir.

\section{Referanslar}

Atalay, İ. (2010). Uygulamalı Klimatoloji. Meta basım Matbaacılık, İzmir.

Çelik, S.,Bacanl, H., Görgeç H., Yayvan, M., Deniz, A. (2007) 16 Kasım 2007 Tekirdağ, 18 Kasım 2007 Marmaris, Bodrum ve Dalaman'da meydana gelen şiddetli yağışların sinoptik analizi, Yayımlanmamış bildiri,wwww.mehmetyayvan.com

Devlet Meteoroloji İşleri Genel Müdürlüğü. (2009) Günlük Sinoptik Haritalar, DMİ Bülteni,Ankara, Türkiye.

Devlet Meteoroloji İşleri Genel Müdürlüğü. (2007). Hava Analiz ve Tahmin Tekniği, DMİ Yayınları, Yayın No: 2006-1, Ankara.

Doswell, C. (1982) The Operational Meteorology of Convective Weather. Volume 1:Operational Meso-analysis, NOAA Tech. Memo. NWS NSSPC-5, III, 40-45.

Gökter, M. (2006) Türkiye'de Taşkın Afetleri ve Sivil Savunma, I.Ulusal Taşkın Sempozyumu Tebliğler Kitabı, 10-12 Mayıs 2006 DSİ Genel Müdürlüğü, Konferans Salonu, Yücetepe, Ankara, 157-163.

Kadığlu, M. (2006) Afetler Konusunda Kamuoyunun Bilinçlendirilmesi ve Eğitim; Kadığlu, M. ve Özdamar, E., eds., 2. bask1, "Afet Yönetiminin Temel İlkeleri" içinde; s. 67-80, JICA Türkiye Ofisi Yayınları No: 1, Ankara.

Kadıŏglu, M. (2008) Küresel İklim Değişikliği ve Uyum Stratejileri, s. 69-94, Kar Hidrolojisi Konferansı, 27-28 Mart, 2008 DSİ VII. Bölge Müdürlüğü Erzurum.

Komuscu, A.U., Erkan A., ve Çelik S. (1998) Meteorological and Terrain Analysis of Izmir Flash Flood of 3-5 November 1995, Natural Hazards, 18, 1-25 (1998).

Kömüşçü, A.Ü., Ceylan, A. (2007) Maksimum Şiddetli Yağış Verilerine Göre Türkiye’de Taşkın Risk Alanlarının Belirlenmesi, V. Ulusal Hidroloji Kongresi, ODTÜ, Ankara.

Maddox, R.A. (1979) A methodology for forecasting heavy convective precipitation and flash flooding, National Weather Digest. Flood, 30-42.

Paddock, M.J.,Graves C.E. (2008) Examining preconvective heavy rainfall environments utilizing observational and model analysis proximity soundings, Saint Louis University, St. Louis, Missouri. 